\title{
DEVELOPMENT OF A FLEXIBLE HIGHER EDUCATION CURRICULUM FRAMEWORK FOR GEOGRAPHIC INFORMATION SCIENCE
}

\author{
Bert Veenendaal \\ Department of Spatial Sciences, Curtin University, GPO Box U1987, Perth, Australia - b.veenendaal@curtin.edu.au
}

\author{
Commission IV, WG IV/5
}

KEY WORDS: GIS, geographic information science, GIScience, geospatial, higher education, curriculum, education development

\begin{abstract}
:
A wide range of geographic information science (GIScience) educational programs currently exist, the oldest now over 25 years. Offerings vary from those specifically focussed on geographic information science, to those that utilise geographic information systems in various applications and disciplines. Over the past two decades, there have been a number of initiatives to design curricula for GIScience, including the NCGIA Core Curriculum, GIS\&T Body of Knowledge and the Geospatial Technology Competency Model developments. The rapid developments in geospatial technology, applications and organisations means that curricula need to constantly be updated and developed to maintain currency and relevance. This paper reviews the curriculum initiatives and outlines a new and flexible GIScience higher education curriculum framework which complements and utilises existing curricula. This new framework was applied to the GIScience programs at Curtin University in Perth, Australia which has surpassed 25 years of GIScience education. Some of the results of applying this framework are outlined and discussed.
\end{abstract}

\section{INTRODUCTION}

\subsection{General Overview}

Geographic information science (GIScience) education programs are now solidly embedded into educational institutions. Offerings range from the use and application of geographic information systems (GIS) applied within different disciplines such as geography or geology, to customisation of GIS tools and models for specific tasks such as environmental management or transportation modelling, to the advancement of GIScience concepts and knowledge including web mapping services and geocomputational modelling.

GIScience programs have developed over the past two to three decades and have undergone numerous evolutions and changes driven by both technologies and the increasing collaborations among users (Li, Dragicevic \& Veenendaal 2011). Not only the rapid developments in technology, but also the application to a diverse range of disciplines and sectors has marked advancements in the geospatial field. The challenge for educators is to maintain the currency and relevance of GIScience curricula to meet the changing needs and demands of industry and government.

\subsection{Aim and scope}

This paper reviews the developments in GIScience curricula in higher education, identifies the challenges and proposes a new framework that not only addresses these challenges, but also provides a means to incorporate and embed rapidly evolving and new developments in a flexible educational environment.

The examples of the GIScience programs at Curtin University in Perth, Australia, are utilised given that Curtin is one of the earliest adopters of GIScience education at the higher education level. After more than two decades of offering GIScience education, these programs recently went through a comprehensive course review process which has served to initiate and inspire the curriculum research outlined in this paper.

\section{BACKGROUND AND DEVELOPMENTS}

\subsection{Development of GIScience higher education}

Educational programs commenced in what was then called the geographic information systems (GIS) discipline approximately two to three decades ago. For example, Curtin University as one of the early providers of GIS education celebrated a 25 year anniversary in 2013 of the delivery of its first GIS program at a graduate diploma level. The same institution also delivered the world's first Bachelor of Science program in GIS commencing in 1992. Since then, the program has developed into a multiplicity of offerings catering for diverse student cohorts at both the undergraduate and postgraduate levels.

The development of GIScience education can be identified as three eras corresponding approximately to the past three decades (Figure 1). The 1990s was marked by the early higher education adopters and focussed on GIS technology and its application across a range of fields including planning, natural resources, infrastructure and agriculture.

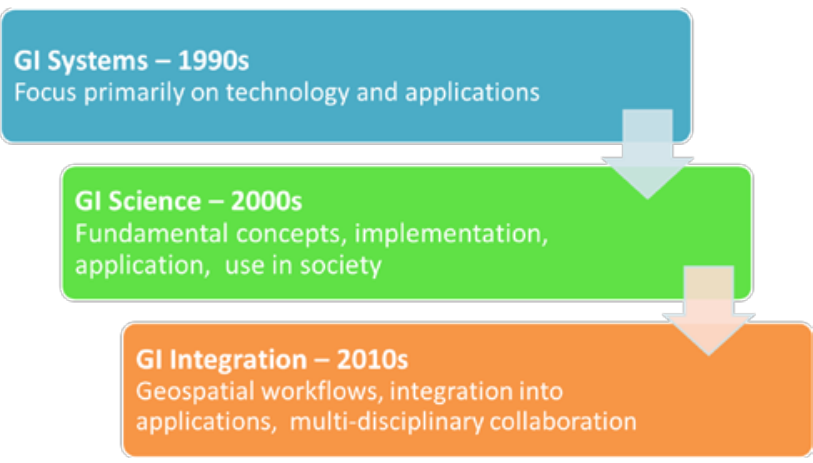

Figure 1: Eras of development in GIScience education 
The second era was an increased focus on the education of the fundamental concepts, implementations and use in society of GIS that underpinned many of its applications. So in addition to simply the understanding and use of the technology, education programs considered the "science" behind the technology including mathematics, analytics, database management, graphics design, cartography, geography and space, etc. Hence the term geographic information science was born (Goodchild, 1992) and many of the educational programs began to focus on the science instead of the systems.

The third and current era is focussed on the integration of geospatial information into organisations, businesses and workflows. It is very much concerned with how geospatial, web, information technologies (IT) and other technologies are integrated and applied into intra- and inter-organisational business workflows and processes. It requires much more collaboration, sharing and contributions of information and knowledge in a multi-disciplinary environment in order to achieve the benefits and value of geospatial information. An example of this is provided by Mulalu \& Veenendaal (2011) who utilised participatory GIS to build and share local knowledge and empower members in a rural community environment.

Technology developments such as the web, semantics and positioning systems have provided an infrastructure for increased collaboration within and between organisations (Veenendaal \& West, 2011). All of these aspects need to be integrated into a holistic geographic information education curriculum.

\subsection{Development of GIScience curricula}

The early GIS educational programs were defined by the learning resources that were available at the time. One of the early textbooks used in GIS education was that of Burrough (1986) which shaped many of the first curricula at colleges and universities, including that of the original program at Curtin University. Since then, a number of curriculum developments and progressions have taken place providing rich resources for educators to draw on (Figure 2).

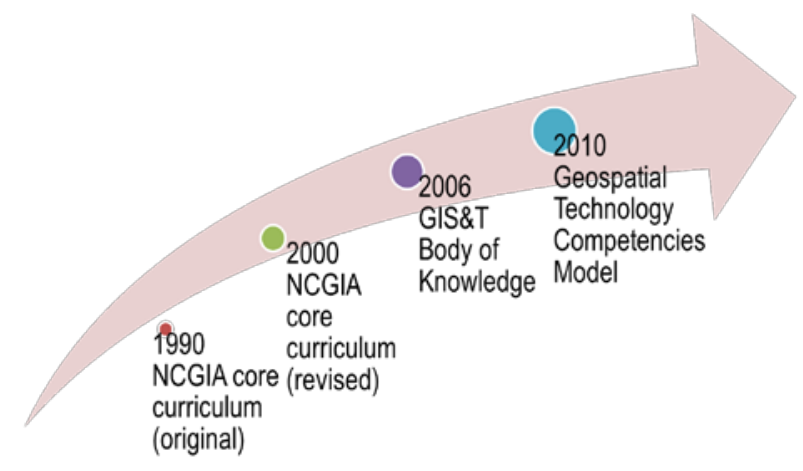

Figure 2: Development of GIScience Curricula

In 1990, the National Center for Geographic Information Analysis developed a core curriculum comprising content and lecture materials to assist educators in geographic information systems (Goodchild \& Kemp, 1990). The result of the effort was the NCGIA Core Curriculum which was made available as 75 units comprising notes and references. The NCGIA Core Curriculum was updated, revised and released in 2000 to incorporate feedback and suggestions, and to accommodate the rapid advances in technology (NCGIA, 2000).

With the fast moving developments in geospatial and information technologies, it was not long before the core curriculum became outdated as regarding the breadth and range of content and knowledge. An effort coordinated by the University Consortium for Geographic Information Science (UCGIS) involved more than 70 educators and resulted in the development of the Geographic Information Science and Technology (GIS\&T) Body of Knowledge (BoK) (Dibiase et al, 2006).

The GIS\&T BoK comprises the subdomains of geographic information science, geospatial technology and applications of GIS\&T. It includes contributions from allied disciplines such as geography, computer science, statistics, mathematics, landscape architecture, psychology and philosophy and can serve a wide range of disciplines and application domains that use or benefit from GIS\&T.

The BoK is intended to serve a range of educational program levels and pathways from primary/secondary education to higher and continuing education. It comprises ten knowledge areas divided into units representing coherent sets of topics which themselves represent a single concept, methodology or technique (Dibiase et al., 2006). Topics are defined in terms of educational objectives, of which there are 1660 in the BoK. These topics and objectives are not prescriptive, but can be utilised selectively and in different combinations for particular educational programs and pathways.

The Geospatial Technology Competencies Model (GTCM) was developed by the United States Department of Labor's Employment and Training Administration (DOLETA) in 2010. The 9-tiered model identifies general and specific competencies including foundational (Tiers 1-3), technical (Tiers 4-5), occupational (Tiers 6-8) and management (Tier 9) (DiBiase et al., 2010). The GTCM is linked to specific industry knowledge and skill needs and hence utilises competencies as a basic building block.

The GTCM is directly linked to specific needs and competencies required by the geospatial industry and sector and related to different occupations and specialisations across the spatial sciences (DOLETA, 2010). The occupational tiers are not more fully detailed in the model, but can be expanded in relation to specific associated occupations as found in the profiles listed on O-NET Online (O-NET, 2014).

The NCGIA core curriculum and the GIS\&T BoK initiatives are largely focussed on the first era of GIScience education with a emphasis on the knowledge and skills of GIS technology and systems.

The BoK does go beyond the technology issues and incorporates infrastructure and society issues in relation to the usage and implementation of the technology in organisational and industry contexts. This is especially apparent through the GIS\&T and Society and the Organisational and Institutional Aspects knowledge areas with 13 units defined (Dibiase et al., 2006).

The GTCM links content to occupational tasks in the form of competencies. Hence it is not just another listing of content and disciplines, but links together personal, academic, workplace, 
industry, occupational and management competencies in an extensive and well defined framework model. The tiers in the model can then be further expanded and flexibly used in the context of particular industries and occupations. The model is two-dimensional but could be expanded in the third dimension to identify domain-specific competencies in the allied fields that utilise geospatial technology and professionals (DOLETA, 2010).

\subsection{Requirements of a higher education GIScience curriculum}

The curricula models identified are very useful in building a GIScience higher education program. The continual development of geospatial technology, society and workplaces adds to the challenge of defining a curriculum that is flexible and expandable over time and disciplines.

For example, the fast evolving field of geospatial web and cloud based mapping is not adequately represented in any of these models. Not only the rapid technology developments, but also the industry-based workflows and business processes have rapidly evolved, and the exposure of web based geospatial information and applications has expanded quickly across a diverse range of disciplines and sectors beyond those traditionally associated with GIS. Any curriculum framework must be able to rapidly adapt to these fast-moving changes and disciplines to remain current and relevant.

There is no such thing as "one size fits all” in GIScience education. This was readily recognised in all of the curriculum developments. The content and lecture notes of the NCGIA Core Curriculum as well as the units and topics with the knowledge areas of the GIS\&T BoK were intended to be selectively and flexibly used and adapted to various programs. The industry and occupational needs of various sectors inform the specific competencies to be included in a GTCM based curriculum.

Within the higher education sector, there is a tendency to generate different educational programs that are customised and cater to the needs of different student cohorts with differing levels of knowledge and skills among students at the point of entry, and aim at producing graduates with different knowledge and skills in line with the appropriate educational qualifications and levels. The result is GIScience programs at the undergraduate degree, postgraduate degree, certificate, professional development and other levels.

For example, Curtin University offers an undergraduate GIScience three year Bachelor program for high school leavers and mature age entrants who only have secondary school qualifications but no skills or experience in the workforce. The graduate certificate and graduate diploma programs are offered to professionals from other disciplines or qualifications who have substantial professional or life-long learning skills that need to be supplemented with geospatial knowledge and skills. A curriculum framework needs to accommodate these different program qualifications and student cohorts.

Additionally, there are programs that may be designed for core geospatial professionals, for professionals in related spatial sciences disciplines (eg. surveying, cartography, remote sensing) and also for professionals from other allied disciplines that use and benefit from geospatial information and technology. For example, Curtin University offers a double degree of GIScience with applied geology. Geospatial skills are also embedded into the mine engineering program at Curtin. A curriculum framework must be sufficiently flexible to cater for the different requirements of each program.

Therefore any higher education GIScience curriculum must be designed to cater for a multi-disciplinary environment, fastdeveloping workplace, diverse student cohort intake, and different levels of graduate knowledge and skills. These requirements were used to develop a framework for GIScience curricula that could be effectively utilised at the higher education level.

\section{FRAMEWORK FOR GISCIENCE HIGHER EDUCATION}

\subsection{Framework requirements and scope}

In order to address the challenges at a higher education level, a curriculum framework was developed for GIScience. It needed to utilise and take advantage of the past work done on GIScience curricula, as well as be able to cater for different student intakes, needs and graduate attributes in line with the constantly changing geospatial technologies, workplaces and environments.

The curriculum framework needed to be just that, a framework, and not a prescriptive list of topics. At the same time, the framework can be implemented in different educational programs at different levels to cater for varying students and industry needs. Further, the framework does not specify the mode of delivery and can be utilised within a range of educational delivery mechanisms including face-to-face, fully distance, online and flexible study modes.

\subsection{GIScience higher education curriculum framework}

The GIScience higher education curriculum (HEC) framework was developed by Curtin University and is illustrated in Figure 3. It was developed by utilising the tiered concepts of the GTCM model, especially in distinguishing the academic and workplace elements of the curriculum. It does not specify the content as the NCGIA and BoK initiatives do. Rather, the existing content-based curricula developments, such as the GIS\&T BoK, can be used to specify and organise content within the framework identified. It is noted that such content will continually need to be updated and developed to incorporate the rapidly changing geospatial environments.

The GIScience HEC framework comprises four tiers which identify knowledge and skills groupings that need to be incorporated into a curriculum based on the graduate attributes required by an education program.

Tier 1 of the framework comprises academic knowledge and skills. This tier involves generic communication and literacy skills such as reading/writing, speaking/listening, mathematics/statistics, critical \& analytical thinking, computer literacy and appreciation of people and places. Depending on the entry level required by the program, it can be assumed that student cohorts will have some of these skills and knowledge. The extent of the skills and knowledge required will vary by program and likewise the extent of what the program incorporates. 


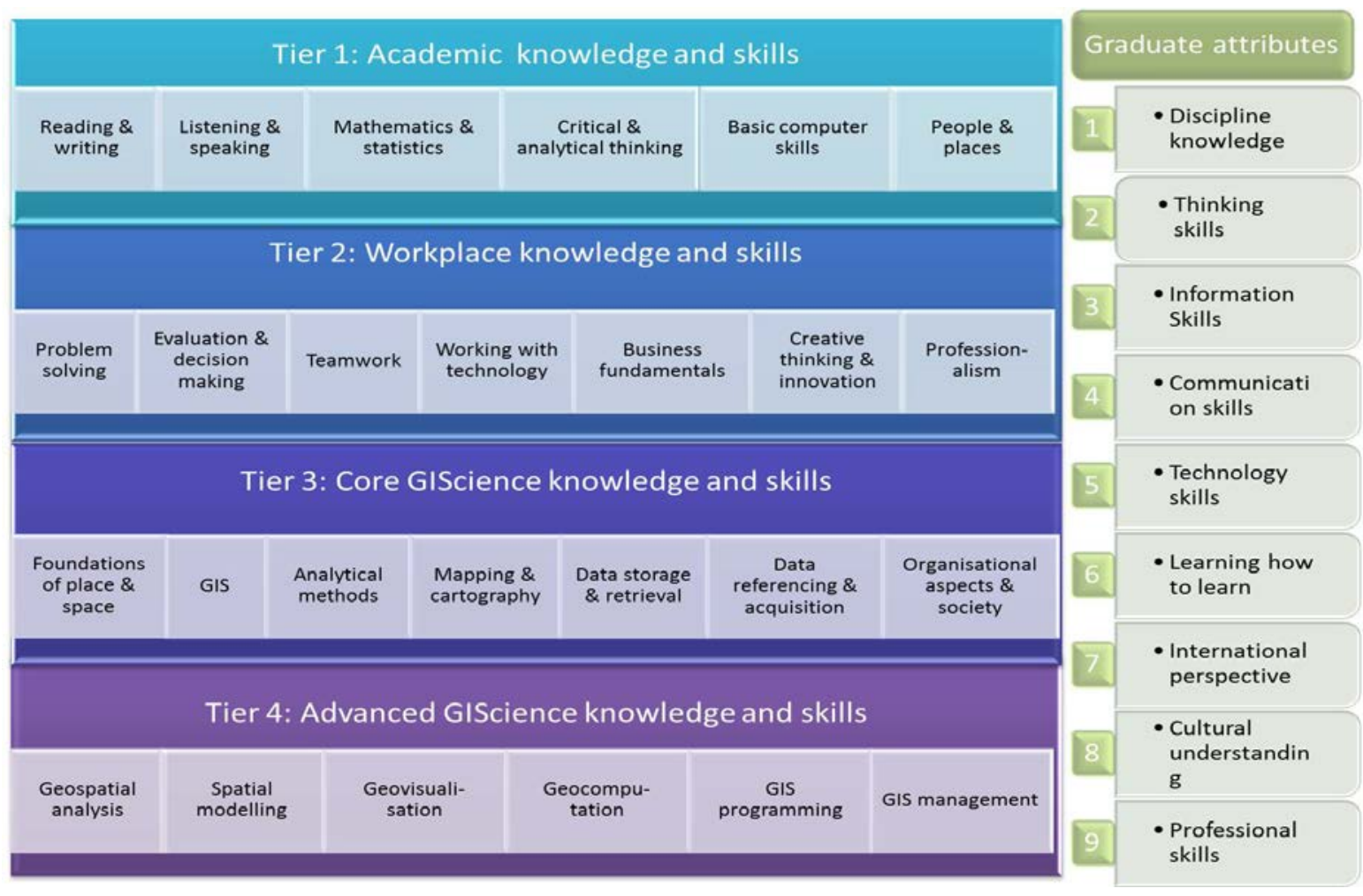

Figure 3: GIScience higher education curriculum framework

The second tier of the framework deals with the skills and knowledge required in the workplace. This includes such aspects as problem solving, teamwork, business fundamentals and professionalism. Student cohorts with backgrounds in the workplace or in other disciplines may have many of these skills already, whereas students freshly out of secondary school and entering an undergraduate degree may lack almost all of this knowledge and skills.

The core GIScience knowledge and skills are identified in the third tier of the framework. These identify the core areas of the discipline that all GIScience programs will draw on. They include the foundations of geography (place and space), GIS basics, analytical methods, mapping, data storage and retrieval, data referencing and acquisition, and organisational aspects and society. Although all programs should comprise these core elements, the level of detail will vary among different programs and student cohorts. For example, geology students requiring geospatial knowledge and skills would draw on topics within each of these core areas, but the knowledge of GIS utilisation or types of data acquisition may vary from a health student doing epidemiological tracking and mapping.

More advanced GIScience knowledge and skills are captured in Tier 4 of the model. These are embedded more commonly in specialist GIScience programs or disciplines requiring strong skills in geospatial analysis and modelling. Advanced skills and knowledge comprise geospatial analysis, spatial modelling, geovisualisation, geocomputation, GIS programming and customisation, and GIS management.

The framework also identifies the graduate attributes towards which the curriculum must be directed. The graduate attributes shown in the model are relatively generic, but are taken from those adopted by Curtin University (Curtin, 2014). They may vary somewhat from institution to institution, and can be replaced as necessary.

This framework specifies the groupings of knowledge and skills at each tier, but does not specify the topics and units that deliver the knowledge and skill groupings. However this is where the GIS\&T BoK can be utilised and expanded where necessary to develop the content appropriate to a particular course offering. It is expected that different course offerings and different institutions would "package" these knowledge and skills in their own unique program structure that bears the stamp and reputation of their own higher educational institution and academic/research staff profiles.

\subsection{Applying the framework model}

The GIScience higher education curriculum framework can be applied to a range of different programs with different needs and requirements. For example, at Curtin University it was applied at both the undergraduate and postgraduate levels in GIScience, as well as in other programs, both within and outside of the spatial sciences.

For the undergraduate programs, much of the Tier 1 knowledge and skills have to be embedded in the courses and units (otherwise known as subjects). For the postgraduate programs, students are expected to have a higher level of academic knowledge and skills based on their prior qualifications and work experiences and hence do not require explicit learning of these skills and knowledge. Instead, this higher level of background can be taken into account in specific units within the assessments and learning outcomes associated with that unit. 
Each course identifies its own course learning outcomes appropriate to the educational qualification level for which it is designed. The knowledge and skills identified in the framework need to be applied as appropriate to the learning outcomes of the particular course. For example, at Curtin University, the Graduate Certificate in Geographic Information Science draws primarily from the Core GIScience Knowledge and Skills tier as it is intended to provide professionals with some basic exposure to GIS, analytical and data handling skills and knowledge. On the other hand, the Master of Science (Geospatial Science) program draws heavily on both Tiers 3 and 4 to incorporate both core and advanced GIScience skills.

The Tier 2 knowledge and skills dealing with the workplace need to be embedded in the undergraduate programs, since the undergraduate student cohort is not expected to have prior work experiences and exposure. On the other hand, postgraduate students already have many or most of these attributes given their prior qualifications and work experiences.

In general, the academic and core skills form the foundational knowledge and skills that are required for more discipline specific units at the core and advanced levels. The workplace skills and knowledge can then be incorporated in the learning program by applying the foundational and discipline knowledge and skills in context. The four tiers need not correspond to the years of the program, but can be interspersed and distributed according to the needs of the particular topic or content within the curriculum.

For example, at Curtin University this was applied to both the GIScience 3-year undergraduate bachelor program as well as to the geospatial requirements for other spatial sciences programs such as the surveying (4-year) and mine \& engineering surveying (3 yr) programs. The result is shown in Figure 4 where the GIScience curriculum framework was applied to the foundational and discipline based units across the different years of the programs.

The first year of the programs is foundational and therefore has a high degree of commonality across the programs. However, the second and successive years of the programs tend towards being discipline-specific applying core and advanced knowledge and skills from the GIScience HEC framework and embedding more workplace knowledge and skills especially within the final year of the programs.

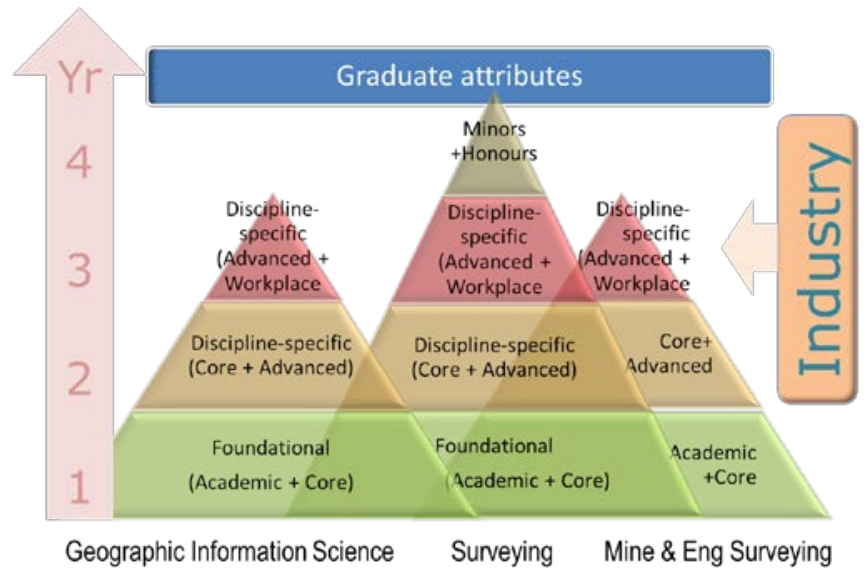

Figure 4: Application of the GIScience curriculum framework to different spatial sciences education programs
To further illustrate the application of the HEC framework, consider, for example, the introductory unit Geographic Information Systems or GIS. The GIS unit is a foundational first-year requirement across multiple programs, in fact within all three spatial sciences programs identified in Figure 4. The unit is based on the Critical \& analytical thinking and Computer skills attributes at the Tier 1 academic level as well as the Foundations of place \& space and GIS attributes at the Tier 3 core level of the GIScience HEC framework (Figure 3).

Another unit called Web Mapping or WM, is discipline specific to the GIScience program and offered in the second year. It utilises the Tier 3 core attributes of GIS, Mapping \& cartography and Data storage \& retrieval, as well as Tier 4 advanced attributes of Geovisualisation and GIS programming (Figure 3). Additionally, because of the rapid advances in web mapping and web GIS technologies and applications, new and updated topics and skills have been introduced into this $W M$ unit within the context of the Tier 3 and 4 attributes already embedded. The GIScience HEC framework provides an overall structure from which the curricula knowledge and skills can be modified, extended and enhanced within one or more programs of study.

The GIS\&T BoK content and topics, along with more recent developments, were used to design and construct each of the units and topics within the GIScience HEC framework for the Curtin University programs. In this way, the existing curricula developments and any such future additions, modifications and enhancements are able to be accommodated within the GIScience HEC framework.

\section{SUMMARY AND CONCLUSIONS}

Given the rapid developments in geospatial technology and the applications within organisations and workplaces, the curriculum for GIScience education needs to constantly adapt. This is a challenge for educators who need to respond to the changing requirements relating to content, flexibility, student cohorts, industry needs, etc. among a range of educational offerings.

This paper identified three eras in GIScience education and outlined some of the notable curriculum developments over those eras, in particular the NCGIA, BoK and GTCM initiatives. These initiatives were utilised to generate a GIScience curriculum framework with a specific focus on higher education curricula. This framework was applied to a range of undergraduate and postgraduate programs at Curtin University.

The GIScience HEC framework provides a flexible approach to dealing with curricula at different qualification levels and catering for students at different levels of entry. The framework does not specify the content nor how it should be organised within a program, but provides the broad framework parameters for embedding GIScience into an educational program at undergraduate or postgraduate levels.

In implementing the GIScience HEC framework at Curtin University, the GIS\&T BoK knowledge areas and units were selectively extracted, applied, extended and reorganised as necessary for different programs of study. This was successfully achieved at both undergraduate and postgraduate levels, as well as for programs within and outside of the core GIScience and spatial sciences disciplines. 
Having commenced the implementation of a range of programs adapted to this new GIScience higher education curriculum framework, the next step is to monitor student progression in relation to learning outcomes. This will then provide a basis to evaluate the effectiveness of this framework in the context of a number of implementations.

It is expected that the breadth and flexibility afforded by this framework will allow GIScience educational programs to adapt and transition according to the rapidly developing and changing needs of the GIScience industry. This will then ensure that GIScience education meets the needs of the expanding industry and that graduates and professionals will receive appropriate and relevant career pathway opportunities.

\section{REFERENCES}

Burrough, P.A. 1986. Principles of Geographical Information Systems for Land Resources Assessment. Oxford University Press, ISBN 0198545924.

Curtin. 2014. Curtin Graduate Attributes. Curtin Teaching and Learning, Curtin University, Perth, Western Australia. http://otl.curtin.edu.au/learning_teaching/graduate_capabilities. cfm (15 Jan 2014).

DiBiase, David, Michael DeMers, Ann Johnson, Karen Kemp \& Ann Taylor Luck (editors). 2006. Geographic Information Science and Technology Body of Knowledge. Association of American Geographers, Washington, USA.

DiBiase, David, Tripp Corbin, Thomas Fox, Joe Francica, Kass Green, Janet Jackson, Gary Jeffress, Brian Jones, Brent Jones, Jeremy Mennis, Karen Schuckman, Cy Smith, \& Jan Van Sickle. 2010. The New Geospatial Technology Competency Model: Bringing Workforce Needs into Focus. URISA Journal, 22:2.

DOLETA. 2010. Geospatial Technology Competency Model. Employment and Training Administration, United States Department of Labour, http://www.careeronestop.org/CompetencyModel/pyramid.aspx ?GEO=Y (1 Jan 2014).

Goodchild, M.F. 1992. Geographical information science. International Journal of Geographical Information Systems, 6:1, pp 31-45.

Goodchild, M.F., and K.K. Kemp, eds. 1990. NCGIA Core Curriculum in GIS. National Center for Geographic Information Analysis, University of California, Santa Barbara CA. http://www.geog.ubc.ca/courses/klink/gis.notes/ncgia/toc.html (15 Jan 2014).

Li, S, B Veenendaal \& S Dragićević. 2011. Advances, challenges and future directions in web-based GIS mapping services. In Li, S, Dragićević, S and Veenendaal B (2011) Advances in Web-based GIS, Mapping Services and Applications, Taylor \& Francis Group, London, ISBN 978-0415-80483-7.

Mulalu, Mulalu. \& Bert Veenendaal. 2011. PGIS Supported Knowledge Based Participation and Evidences of Empowered Community Members. Proceedings of ISDE 7th International Symposium on Digital Earth, Aug 23, 2011, Perth, Australia, http://espace.library.curtin.edu.au/cgibin/espace.pdf?file=/2012/02/17/file_1/172463 (6 Sep 2013).

NCGIA. 2000. The NCGIA Core Curriculum in GIScience. National Center for Geographic Information Analysis,
University of California, Santa Barbara CA. http://www.ncgia.ucsb.edu/giscc/aboutgiscc.html (15 Jan 2014).

O-NET. 2014. O-NET OnLine: Find Occupations. O-NET OnLine, a partner of the AmericanJobCenter network. http://www.onetonline.org/find (15 Jan 2014).

Veenendaal, Bert \& West, Geoff. 2011. Transforming location intelligence through geospatial web-based technologies. 2nd ISPRS Workshop on Pervasive Web Mapping, Geoprocessing and Services: Our Complex World, 10 August, Simon Fraser University, British Columbia, Canada.

\section{ACKNOWLEDGEMENTS}

Through its comprehensive course review (CCR) process, Curtin University provided the opportunity to review and reflect on the GIScience curriculum developed over several decades. The contribution and assistance of colleagues in the Department of Spatial Sciences and the Curtin Teaching and Learning group as well as student feedback and evaluations are gratefully acknowledged. I would also like to acknowledge the constructive and insightful feedback received from the independent reviewers that served to enhance this paper. 